\title{
Article \\ PUFA Treatment Affects C2C12 Myocyte Differentiation, Myogenesis Related Genes and Energy Metabolism
}

\author{
Marua Abu Risha ${ }^{1}$, Puntita Siengdee ${ }^{1}{ }^{\oplus}$, Dirk Dannenberger ${ }^{3}{ }^{\circ}$, Klaus Wimmers $^{2,4}{ }^{\oplus}$ \\ and Siriluck Ponsuksili $1, *$ (D) \\ 1 Functional Genome Analysis Research Unit, Institute of Genome Biology, Leibniz Institute for \\ Farm Animal Biology (FBN), Wilhelm-Stahl-Allee 2, D-18196 Dummerstorf, Germany; \\ risha@fbn-dummerstorf.de (M.A.R.); siengdee@fbn-dummerstorf.de (P.S.) \\ 2 Genomics Research Unit, Institute of Genome Biology, Leibniz Institute for Farm Animal Biology (FBN), \\ Wilhelm-Stahl-Allee 2, D-18196 Dummerstorf, Germany; wimmers@fbn-dummerstorf.de \\ 3 Lipid Metabolism and Muscular Adaptation Workgroup, Institute of Muscle Biology and Growth, \\ Leibniz Institute for Farm Animal Biology (FBN), Wilhelm-Stahl-Allee 2, \\ D-18196 Dummerstorf, Germany; dannenberger@fbn-dummerstorf.de \\ 4 Faculty of Agricultural and Environmental Sciences, University Rostock, 18059 Rostock, Germany \\ * Correspondence: ponsuksili@fbn-dummerstorf.de; Tel.: +49-38208-68703; Fax: +49-38208-68702
}

Citation: Risha, M.A.; Siengdee, P.; Dannenberger, D.; Wimmers, K.; Ponsuksili, S. PUFA Treatment Affects C2C12 Myocyte Differentiation, Myogenesis Related Genes and Energy Metabolism. Genes 2021, 12, 192. https://doi.org/ 10.3390/genes12020192

Academic Editor: Corrado Angelini Received: 23 December 2020

Accepted: 26 January 2021

Published: 28 January 2021

Publisher's Note: MDPI stays neutral with regard to jurisdictional claims in published maps and institutional affiliations.

Copyright: (c) 2021 by the authors. Licensee MDPI, Basel, Switzerland. This article is an open access article distributed under the terms and conditions of the Creative Commons Attribution (CC BY) license (https:// creativecommons.org/licenses/by/ $4.0 /)$.

\begin{abstract}
Polyunsaturated fatty acids (PUFAs) are the main components of cell membrane affecting its fluidity, signaling processes and play a vital role in muscle cell development. The effects of docosahexaenoic acid (DHA) on myogenesis are well known, while the effects of arachidonic acid (AA) are largely unclear. The purpose of this study is to evaluate the effect of two PUFAs (DHA and AA) on cell fate during myogenic processes, Wnt signaling and energy metabolism by using the $\mathrm{C} 2 \mathrm{C} 12$ cells. The cells were treated with different concentrations of AA or DHA for $48 \mathrm{~h}$ during the differentiation period. PUFA treatment increased mRNA level of myogenic factor 5 (Myf5), which is involved in early stage of myoblast proliferation. Additionally, PUFA treatment prevented myoblast differentiation, indicated by decreased myotube fusion index and differentiation index in parallel with reduced mRNA levels of myogenin (MyoG). After PUFA withdrawal, some changes in cell morphology and myosin heavy chain mRNA levels were still observed. Expression of genes associated with Wnt signaling pathway, and energy metabolism changed in PUFA treatment in a dose and time dependent manner. Our data suggests that PUFAs affect the transition of $\mathrm{C} 2 \mathrm{C} 12$ cells from proliferation to differentiation phase by prolonging proliferation and preventing differentiation.
\end{abstract}

Keywords: C2C12; energy metabolism; glycolysis; oxidative phosphorylation; PUFA; fatty acids; myogenesis; Wnt signaling

\section{Introduction}

Myogenesis is a complex process involving many events including proliferation, differentiation and migration of myoblasts, and is regulated by several signaling pathways such as Wnt, BMP and Shh [1,2]. Myogenic regulatory factors (MRFs) are a part of this complex network and regulate embryonic myogenesis, drive muscle regeneration, and repair damage by activating satellite cells. MRFs are specific transcriptional activator factors of muscle-specific genes including myogenin (MyoG), myogenic myogenic differentiation (MyoD), myogenic factor 5 (Myf5) and myogenic factor 6 (Myf6) [3]. Myf5 is the earliest MRF to be expressed during embryonic development [4]. Myf5 enhances myoblasts expansion, while MyoD determines myoblast differentiation prospect. MyoD and MyoG acts together with myocyte enhancer factor 2 (MEF2) to drive differentiation [5]. Myf6 regulates the final differentiation of myotubes [6]. Besides this complex network, cell membrane properties (receptors, channels, lipid composition and polarity) are also considered strong players in myogenesis [7] and key elements for maintaining cell physiology and 
cell survival. Cell membranes consist of two layers which are primarily composed of phospholipids and also contain cholesterols and sphingolipids [8]. The diversity of membrane depends on the fatty acids in the tails of phospholipids. In particular, polyunsaturated fatty acids (PUFAs), long fatty acids with more than one double bond, can change the functionality of membranes. Both n-3-PUFAs $(\omega-3)$ and n-6-PUFAs $(\omega-6)$ are considered important molecular components regulating various functions such as anti-inflammatory and pro-inflammatory properties $[9,10]$. A recent study reported that arachidonic acid (AA, C20:4 n-6) and eicosapentaenoic acid (EPA, C20:5 n-3) reduce cholesterol efflux from cholesterol-loaded macrophages, while docosahexaenoic acid (DHA, C22:6n-3) had no impact on the mouse macrophages [11]. Many fatty acids including oleic acid (OA), linoleic acid (LA), $\gamma$-linoleic acid (GLA), arachidonic acid (AA) and cis-9, trans-11 conjugated linoleic acid ( $\mathrm{c} 9, \mathrm{t} 11$ CLA) can modulate myoblast proliferation and myogenic differentiation $[12,13]$. EPA and DHA pose an inhibitory effect on myoblast proliferation and differentiation, and downregulate muscle-related gene expression [14].

Fatty acids intake changes skeletal muscle lipid composition and membrane fluidity by incorporating into the membrane and remodeling the microdomains, which can affect many cellular signaling processes [15-18]. Wnt signaling pathway is crucial for myogenesis [19], and such signaling pathways are highly active during embryonic development [20] and muscle regeneration [21]. Wnt signaling pathway is not only involved in to cell proliferation, differentiation, migration and survival, but also regulates self-renewal of stem cells and tumorigenesis $[22,23]$. A previous study reported that some n-3 PUFAs reduce oxidative stress [24], possibly by suppressing lipid peroxidation [25]. Most studies focused on the biological effects of EPA and DHA on C2C12 myoblast proliferation and differentiation and the results are still inconsistent [26]. In addition, the link between myogenesis related gene including Wnt signaling and energy metabolism on $\mathrm{C} 2 \mathrm{C} 12$ myoblast proliferation and differentiation after modulation with AA and DHA is still unclear. In this study, we used $\mathrm{C} 2 \mathrm{C} 12$ cells as a model for the myogenesis to evaluate the effect of different concentrations of DHA and AA on myogenesis, regulation of Wnt signaling and energy metabolism.

\section{Materials and Methods}

\subsection{Cell Culture}

C2C12 cells passage 11 (ATCC ${ }^{\circledR}$ CRL1772 ${ }^{\mathrm{TM}}$, LGC Standards GmbH, Wesel, Germany) were maintained in complete growth medium (GM containing Dulbecco's Modified Eagle's medium [+] $4.5 \mathrm{~g} / \mathrm{L}$ D-Glucose, L-Glutamine [-] Pyruvate (DMEM, Gibco, New York, NY, USA), supplemented with 10\% fetal bovine serum (FBS, Sigma-Aldrich, Taufkirchen, Germany) and 1\% Antibiotic Antimycotic solution (Sigma-Aldrich, Taufkirchen, Germany) at $37^{\circ} \mathrm{C}$ under $5 \% \mathrm{CO}_{2}$. The cells were detached using $0.125 \%$ Trypsin-EDTA (Biochrom, Berlin, Germany).

\subsection{PUFA Preparation for In Vitro Culture}

PUFAs used in our experiment were prepared by conjugating either docosahexaenoic acid (Sigma-Aldrich, D2534) or arachidonic acid (Sigma-Aldrich, A3611) with fatty acid free bovine serum albumin (BSA) at $4: 1$ ratio and stored at $-20^{\circ} \mathrm{C}$. The fatty acids were mixed with $1 \mathrm{~mL}$ methanol and evaporated under nitrogen gas stream. BSA/PBS solution was added to the mix, sonicated for 1 hour, and $\mathrm{pH}$ was adjusted to 7.4 with $1 \mathrm{~N}$ sodium hydroxide $(\mathrm{NaOH})$.

\subsection{Assessment of PUFA Effect on Cell Viability by xCELLigence Real-Time Assay}

The xCelligence Real Time Cell Analyzer (RTCA) System was used to determine cell viability in real-time as reflected by cell proliferation. The optimum PUFA concentration and duration of treatment were first tested by measuring the cell index. In this experiment, 5000 cells/well were seeded in 16-well plates with complete growth medium under above described conditions. The cells were allowed to attach for $5 \mathrm{~h}$ and then AA or DHA was added to the wells at four concentrations $(20,30,50,100 \mu \mathrm{M})$. Equivalent concentrations 
of BSA $(4.7,7.1,11.8$ and $23.7 \mu \mathrm{M})$ were used as positive controls. Three replicates were used for each treatment and cellular impedance was measured every $0.5 \mathrm{~h}$ for $72 \mathrm{~h}$. The experimental code is described in Table 1. The data from xCelligence were collected with the system software. Normalized cell index is the cell index value adjusted to 1 at the start time of PUFA treatment. The normalization function of the software converts all values to a proportion of 1 [27]. The non-toxic concentration of PUFAs for C2C12 was determined based on their negative impact on cell proliferation.

Table 1. The experimental code used in xCELLigence RTCA system.

\begin{tabular}{ll}
\hline Code & Treatment (Conditions) \\
\hline AA20 & Arachidonic acid $20 \mu \mathrm{M}+\mathrm{BSA} 4.7 \mu \mathrm{M}$ \\
AA30 & Arachidonic acid $30 \mu \mathrm{M}+\mathrm{BSA} 7.1 \mu \mathrm{M}$ \\
AA50 & Arachidonic acid $50 \mu \mathrm{M}+\mathrm{BSA} 11.8 \mu \mathrm{M}$ \\
AA100 & Arachidonic acid $100 \mu \mathrm{M}+\mathrm{BSA} 23.7 \mu \mathrm{M}$ \\
DHA20 & Docosahexaenoic acid $20 \mu \mathrm{M}+\mathrm{BSA} 4.7 \mu \mathrm{M}$ \\
DHA30 & Docosahexaenoic acid $30 \mu \mathrm{M}+\mathrm{BSA} 7.1 \mu \mathrm{M}$ \\
DHA50 & Docosahexaenoic acid $50 \mu \mathrm{M}+\mathrm{BSA} 11.8 \mu \mathrm{M}$ \\
DHA100 & Docosahexaenoic acid $100 \mu \mathrm{M}+\mathrm{BSA} 23.7 \mu \mathrm{M}$ \\
BSA20 & Bovine Serum Albumin $4.7 \mu \mathrm{M}$ \\
BSA30 & Bovine Serum Albumin $7.1 \mu \mathrm{M}$ \\
BSAA50 & Bovine Serum Albumin $11.8 \mu \mathrm{M}$ \\
BSA100 & Bovine Serum Albumin $23.7 \mu \mathrm{M}$ \\
\hline
\end{tabular}

\subsection{Cell Differentiation Experiment}

The C2C12 of cell passage 11 were seeded in 6-well/plates in room temperature for $30 \mathrm{~min}$ to assure the attachment on the plastic surface, and then cultured at $37{ }^{\circ} \mathrm{C}$ under $5 \% \mathrm{CO}_{2}$. To induce differentiation, culture medium was switched to differentiation medium (DM) Dulbecco's Modified Eagle's medium [+] 4.5 g/L D-Glucose, L-Glutamine [-] Pyruvate (DMEM, Gibco), supplemented with 2\% horse serum (HS, Sigma) and 1\% Antibiotic Antimycotic solution (Sigma) at $37{ }^{\circ} \mathrm{C}$ under $5 \% \mathrm{CO}_{2}$. DHA and AA were added to DM in two concentrations (20 and $50 \mu \mathrm{M})$ separately. BSA was added in two concentrations correspond to the PUFA (4.74 $\mu \mathrm{M}$ (BSA20) and 11.85 $\mu \mathrm{M}$ (BSA50)). After $48 \mathrm{~h}$ of treatment, the culture medium was switched back to DM without PUFA. Cells were collected for RNA isolation at different time points; differentiated cells (d2) after $48 \mathrm{~h}$ of treatment, after $48 \mathrm{~h}$ treatment plus 2 days of recovery (d4), and after $48 \mathrm{~h}$ treatment plus 6 day of recovery (d8) (Figure 1). Three independent replicates were performed for each group.

\subsection{Quantitative Real-Time PCR}

Total RNA was isolated from each treatment group using TRI reagent (Sigma-Aldrich, Taufkirchen, Germany) according to the manufacturer's instructions, followed by a purification step using RNeasy MiniKi (Qiagen, Hilden, Germany) and DNase I to remove any trace of DNA. Quantitative reverse transcriptase PCR (RT-qPCR) was performed using Superscript II reverse transcriptase (Invitrogen, Carlsbad, CA, USA), oligo(dT), with specific target amplification (STA) and Exonuclease I (Exo-I) treatment. The qPCR analyses were performed via BioMark HD Real-time PCR System (Fluidigm, South San Francisco, CA, USA) using $48 \times 48$ dynamic array with an integrated fluidic circuit (IFC). For the assay mix, $2.5 \mu \mathrm{L}$ assay loading reagent, $2.3 \mu \mathrm{L}$ DNA suspension buffer and $0.25 \mu \mathrm{L}$ of a $100 \mu \mathrm{M}$ primer solution were used (forward and reverse primers provided in Supplementary Table S1). The master mix for sample plate consists of $2.5 \mu \mathrm{L}$ SsoFast EvaGreen supermix with low ROX (Biorad, Hercules, CA, USA), $0.25 \mu \mathrm{L}$ DNA binding dye and 2.25 $\mu \mathrm{L}$ STA and Exo-I. The thermal conditions were $95^{\circ} \mathrm{C}$ for $60 \mathrm{~s}$ for initial denaturation, 30 cycles of denaturation at $95^{\circ} \mathrm{C}$ for $5 \mathrm{~s}$ and annealing at $60^{\circ} \mathrm{C}$ for $20 \mathrm{~s}$. Data analysis was done by the $2^{-\Delta \mathrm{Ct}}$ method. The reference genes Gapdh and Mrps27 were used as housekeeping control, which showed no significant changes in DHA, AA or BSA treatments. Selection of candidate Wnt pathway 
genes were based on their role in the pathway. It included inhibitors (Wif1, Dkk1 and Sfrp1), regulators (rspo1, Cby1, Tnks2, Porcn and Znrf3), specific components of Wnt/PCP pathway (Ror2, Daam1, FZD7 and Rac1), Wnt/Ca ${ }^{+2}$ pathway (Ppp3ca), Wnt/ $\beta$-Catenin pathway (Axin2, Lrp5, Lrp6 and Csnk1g2) and a key player in all Wnt pathways (Dvl2). Other genes were selected based on their role in metabolism (PGC-1 $\alpha$, Prkaa1 and Sirt1) and myogenesis (Myf5, Myf6, MyoD1, MyoG, Myf6, Myh1, Myh2 and Myh4). All genes and primers are listed in Supplementary Table S1. All experiments were performed three times independently.
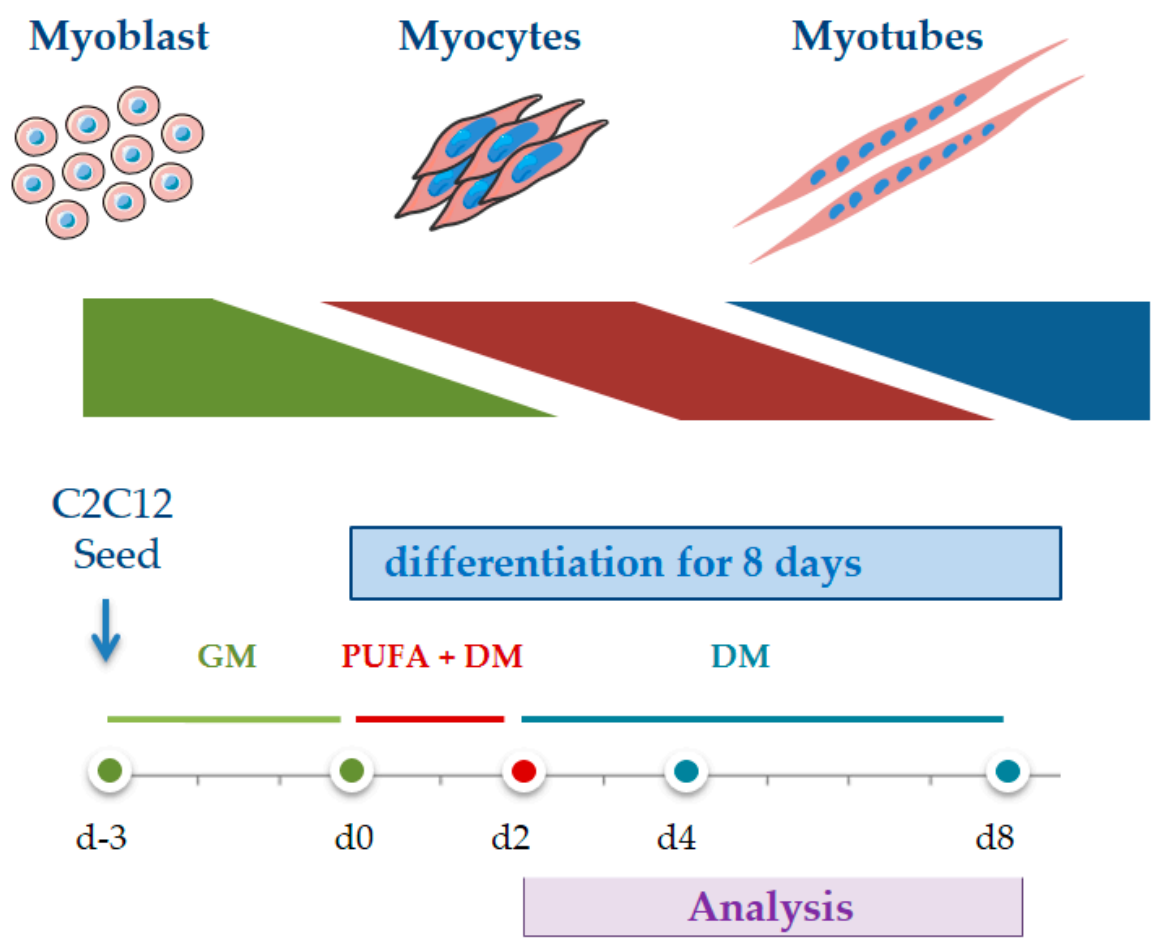

Analysis in different time points

$$
\begin{aligned}
& \begin{array}{lll} 
& \text { Q } & \text { Quantitative real-time PCR } \\
\text { Day } 2 & \text { Immunofluorescence assays } \\
& \text { - } & \text { Bioenergetics assay }
\end{array} \\
& \begin{array}{l}
\text { Day } 4 \\
\text { Day } 8
\end{array} \quad \text { Quantitative real-time PCR }
\end{aligned}
$$

Figure 1. Summary of the experimental design of differentiation experiment. GM = growth medium; $\mathrm{DM}=$ differentiation medium.

\subsection{Immunofluorescence Assays}

After treatment with DHA, AA and BSA for $48 \mathrm{~h}, \mathrm{C} 2 \mathrm{C} 12$ cells were fixed in $4 \%$ formaldehyde for $10 \mathrm{~min}$ and then washed 3 times with PBS for $5 \mathrm{~min}$ each. The cells were permeabilized with $0.5 \%$ Triton X-100 for $10 \mathrm{~min}$, followed with 3 washes with PBS for $5 \mathrm{~min}$. Blocking was done for $1 \mathrm{~h}$ with blocking buffer consisting of $10 \% \mathrm{PBS}, 1 \% \mathrm{BSA}$ and $0.3 \%$ Triton X-100. Then, the cells were incubated with anti-myogenin Alexa488 green (1:300, 53-5643-82, eBioscience ${ }^{\mathrm{TM}}$ by Thermo Fisher, Schwerte, Germany) for one $\mathrm{h}$ at $4{ }^{\circ} \mathrm{C}$ in dark. After two PBS washes, cells were incubated with Hoechst $33342(0.2 \mu \mathrm{g} / \mathrm{mL}, \mathrm{H} 1399$, Invitrogen by Thermo fisher) for $5 \mathrm{~min}$ in dark. The cells were then washed once with PBS and once with water. Fluorescence imaging was obtained with CC-12 high-resolution color camera (OSIS) connected to Nikon Microphot SA fluorescence microscope (Nikon) 
and analyzed with CELL^F software. For each treatment multiple photos were taken and in each field. Myotubes number, number of nuclei incorporated in myotubes, and the total number of nuclei were scored. The differentiation index was calculated by counting the number of nuclei showing Alexa 488 staining divided by the total number of nuclei from the same field. The Fusion index was calculated by counting the number of nuclei in myotubes containing more than 2 nuclei divided by the total number of nuclei from the same field.

\subsection{Bioenergetics Assay}

C2C12 cells were incubated with DHA, AA or BSA for $48 \mathrm{~h}$ to differentiate to myotubes. For measuring energy metabolism, the treated cells were processed to measure glycolytic activity/extracellular acidification rate (ECAR) with the Seahorse XF Glycolysis kit, and mitochondrial function/oxygen consumption rate (OCR) with the Seahorse Cell Mito Stress Test kit. Glycolysis Stress Test is the standard assay for measuring glycolytic function in cells via the direct measurement of the ECAR in real time. Therefore glucose, oligomycin, and 2-deoxyglucose were added sequentially to reveal and analyses the key function of the glycolytic pathway. The XF Cell Mito Stress Test measures key parameters of mitochondrial function by directly measuring the oxygen consumption rate of cells. This test uses modulators of respiration targeting components of the electron transport chain in the mitochondria to reveal key parameters of metabolic function. After 2 days of treatments (BSA20, AA20, DHA20, BSA50, AA50 and DHA50), the growth medium including treatments were removed from the wells and replaced with XF Assay Medium. The details of this procedure were recently described by Sajjanar [28]. Bradford protein assay was used to measure protein in each well for normalization of OCR and ECAR values.

\subsection{Data Analysis}

The normalized data from xCELLigence, bioenergetics assay, differentiation index and fusion index were used as input for analysis using SAS programs. Treatment was considered as fixed effect. An adjustment for multiple comparisons across the Type 3 tests for the fixed effect was calculated using the post hoc Tukey-Kramer test and $p<0.05$ was considered statistically significant. The gene expression levels were subjected to a mixedmodel analysis of variance using JMP Genomics (Proc Mixed; SAS Institute, Rockville, MD, USA). Treatment and day were used as fixed effects. Additionally, replicates were used as random effect, $p<0.05$ was considered statistically significant.

\section{Results}

\subsection{Assessment of PUFA Effect on Cell Viability}

The xCelligence RTCA system records cell impedance as a function of cell density and was used to monitor cell viability of C2C12 cells treated with PUFA (DHA or AA). Cell viability correlates with cell proliferation. Between 24 and $36 \mathrm{~h}$ the cells were in the growth phase and during this time the effect of the high PUFA concentration $(100 \mu \mathrm{M})$ on cell proliferation was visible and significantly different from the control (Figure 2a). When compared with control (BSA), the cell proliferation, shown as cell index, was significant lower with the addition of DHA $(100 \mu \mathrm{M})$ after $24 \mathrm{~h}$, while the same effect was monitored on $100 \mu \mathrm{M}$ AA after $30 \mathrm{~h}$ and $36 \mathrm{~h}$ (Figure $2 \mathrm{~b}$ ). Other concentrations of PUFAs $(20,30$ and $50 \mu \mathrm{M})$ did not affect cell proliferation compared to control (BSA) during 3 days of treatment. Based on these results, we decided to use PUFAs at 20 and $50 \mu \mathrm{M}$ concentrations for further experiments. 
(a)
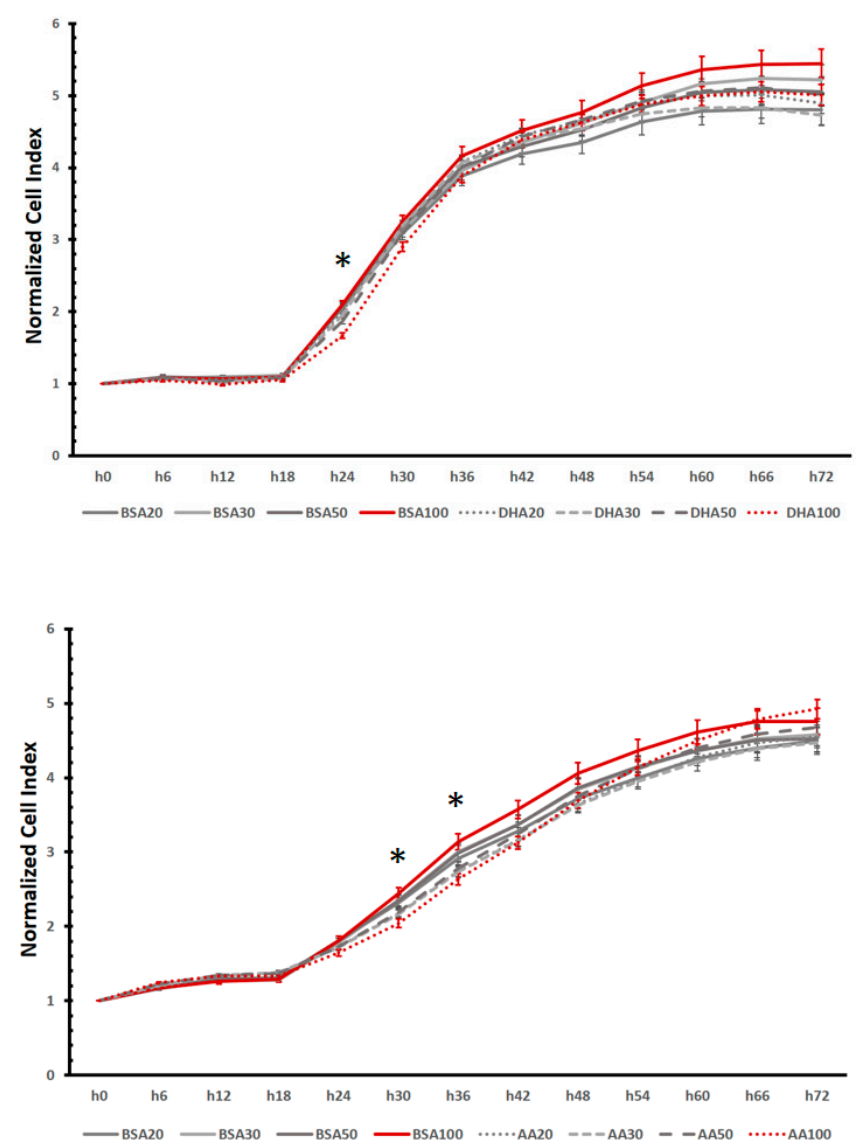

(b)
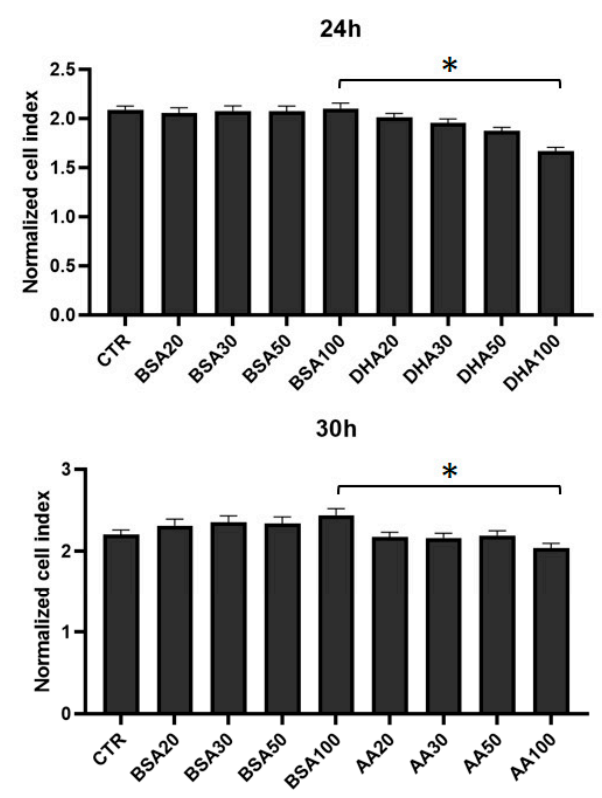

$36 \mathrm{~h}$

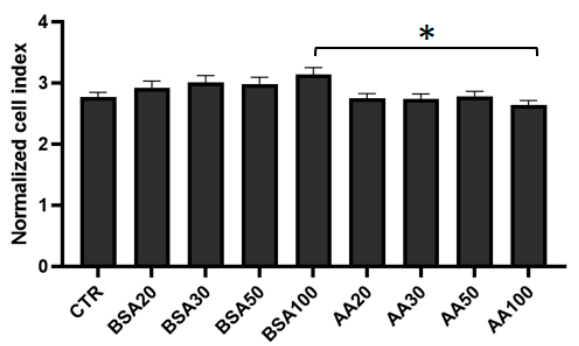

Figure 2. The effect of PUFA treatment on $\mathrm{C} 2 \mathrm{C} 12$ cell proliferation. The changes were observed in real-time with the xCELLigence system after DHA and AA treatments. (a) The normalized cell index for all treatments is shown with dot lines (DHA or AA) and the respective BSA control for each group with solid lines. The cells were exposed to 20, 30, 50 and $100 \mu \mathrm{M}$ of DHA or AA. The red solid line represents the concentration of BSA100 and the red dot line represents the concentration of DHA100 or AA100. (b) Monitoring living cells showed three time points when PUFA treatments at high doses reduced C2C12 proliferation. After $24 \mathrm{~h}$, the cell index showed a decrease with DHA100 (100 $\mu \mathrm{M})$ but no changes in DHA20, DHA30 or DHA50. After 30 and $36 \mathrm{~h}$, the cell index showed a significant decrease with AA100 but no changes were observed in AA20, AA30 or AA50 treatments. Error bars indicate standard error of the mean (SEM), the asterisk * indicate significance between PUFA and equivalent BSA control at $p<0.05$. The scale of the Y-axis corresponds to the normalized cell index of (a) with the same time point. CTR refers to control, i.e., GM without AA or DHA or BSA.

\subsection{AA and DHA Reduced Myogenic Differentiation}

After 2 days of treatments, all concentrations of AA or DHA (AA20, AA50, DHA20 and DHA50) led to a significant reduction in myogenic differentiation of C2C12 cells compared to control (Figure $3 \mathrm{a}, \mathrm{b}$ or Figure $4 \mathrm{a}, \mathrm{b}$ ). The differentiated cells nuclei showed bright green color of anti-myogenin Alexa488 staining. The differentiation efficiency of AA20, AA50, DHA20 and DHA50 treated cells was reduced to 25\%, 29\%,34\% and 50\% respectively compared to control. The fusion efficiency of AA20, AA50, DHA20 and DHA50 treated cells was reduced to $62 \%, 77 \%, 66 \%$ and $90 \%$, respectively, compared to control. In addition, the results showed that DHA treatment causes higher reduction in myogenic differentiation compared to AA treatment. 
(a)
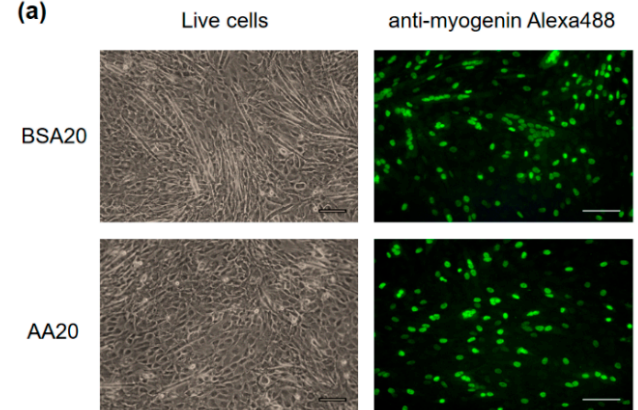

Hoechst33342

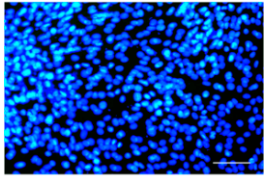

Merged
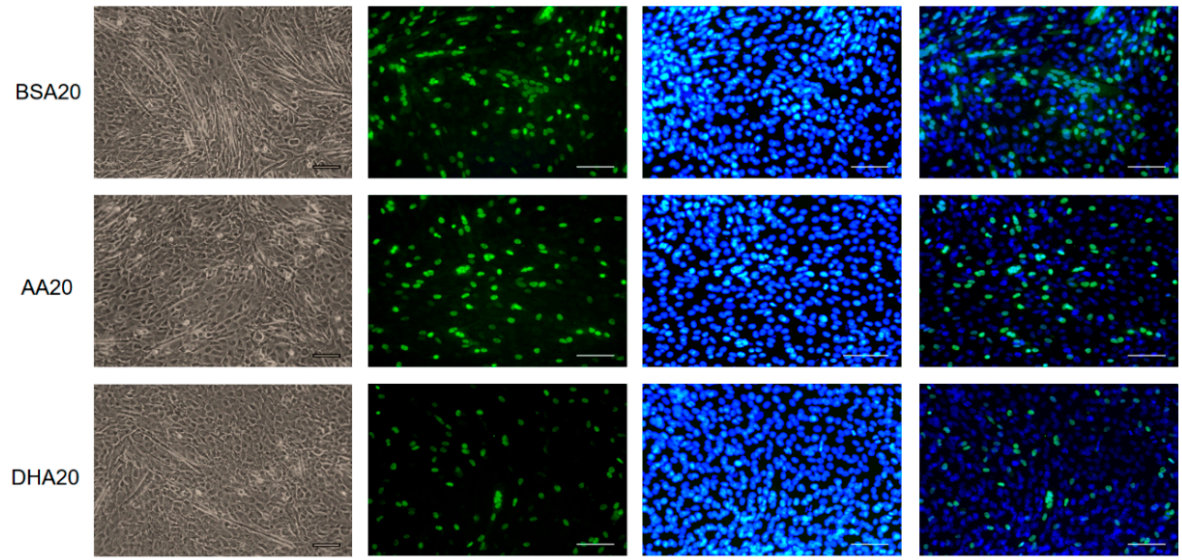

(b)
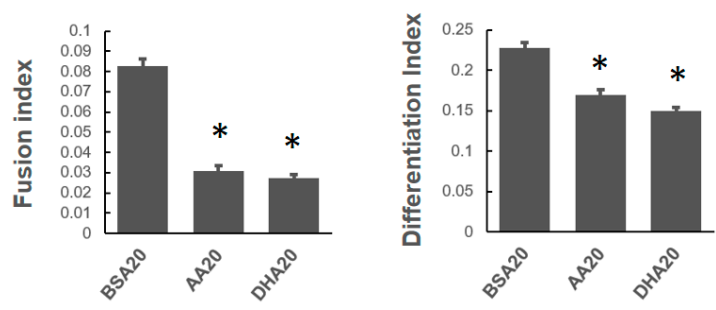

(c)
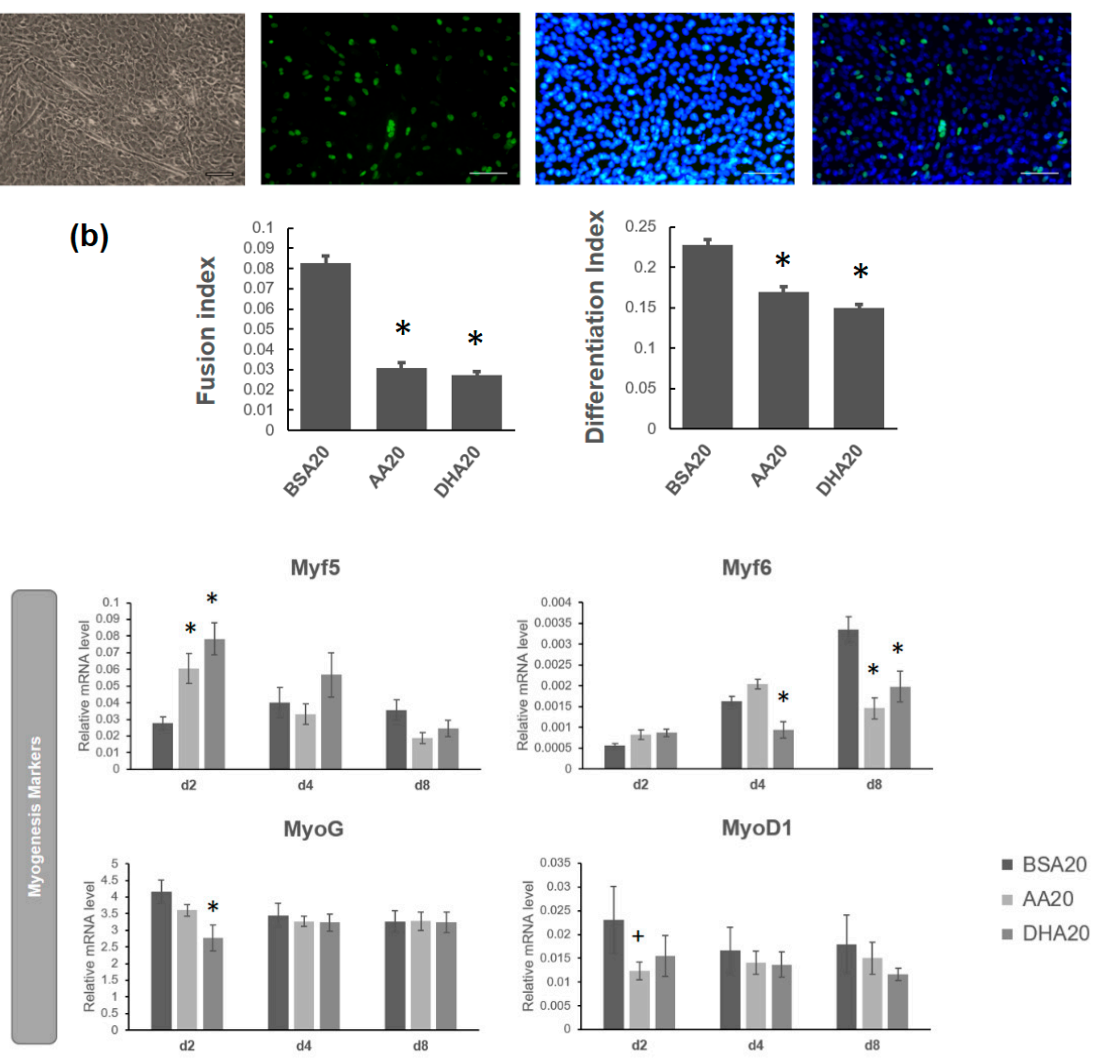

(d)
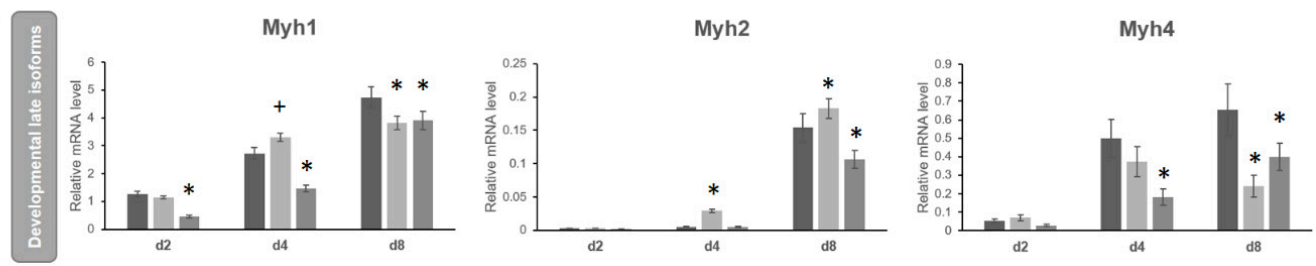

Figure 3. The effect of $20 \mu \mathrm{M}$ PUFA on C2C12 myotubes formation. (a) Immunofluorescence staining using Anti-Myogenin Alexa Fluor $^{\circledR} 488$ and Hoechst 33342 staining on C2C12 myotubes at day 2 (d2) of the treatment. Scale bar for live cells is $100 \mu \mathrm{m}$, Scale bar for anti-myogenin Alexa488, Hoechst 33342 staining and merged is $200 \mu \mathrm{M}$. (b) Quantification of differentiation index and fusion index are shown. The mRNA level of myogenesis markers at three time points ( $\mathrm{d} 2$ (2 days treatment), d4 (2 days treatment plus 2 days recovery), d8 (2 days treatment plus 6 days recovery)) was showed. (c) At d2, Myf5 expression level was induced in both AA20 and DHA20 treatments. MyoG expression level was significantly decreased in DHA20 treatment. MyoD1 expression level was decreased in AA20 treatment. The expression of Myf6 significantly decreased at d4 in DHA20, and significantly decreased in both AA20 and DHA20 at d8. (d) The expression levels of Myh1 significantly decreased at d2, d4 and d8 in DHA20 and in AA20 at d8. The expression levels of Myh2 significantly increased in d4 and d8 in AA20 and significantly decreased in DHA20 at d8. The expression levels of Myh4 significantly decreased at d4 in DHA20 and in both AA20 and DHA20 at d8. All values are LS means \pm SEM, + indicate $p<0.1$ and * indicates $p<0.05$ treatment vs. control group BSA20. 
(a)
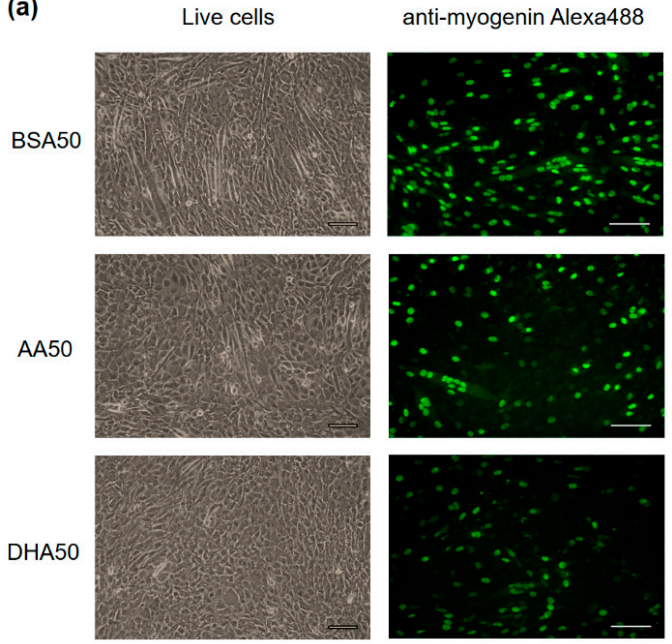

(b)

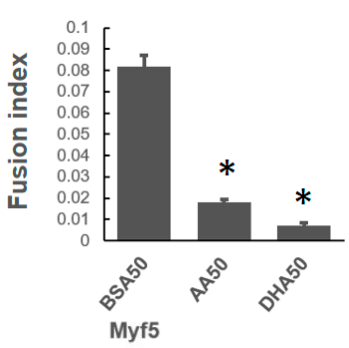

Hoechst33342
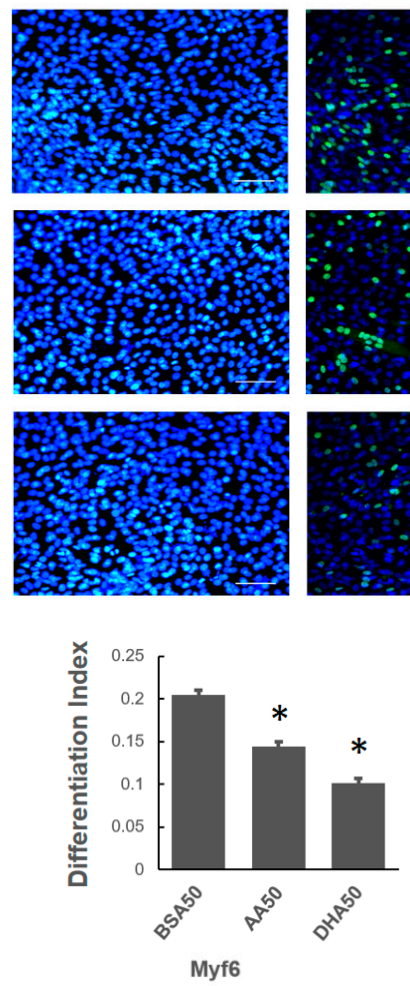

(c)
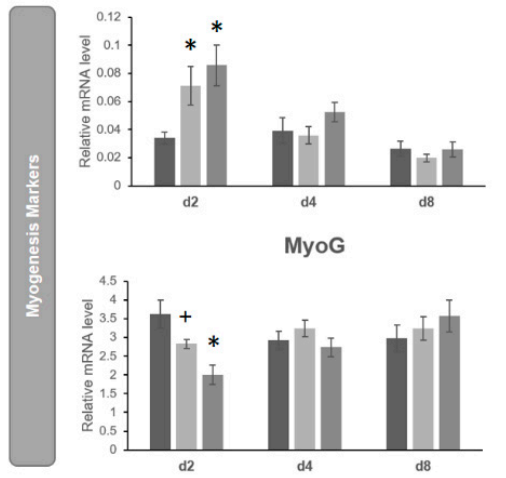

(d)

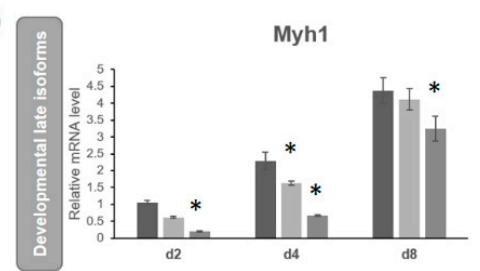

Myh2

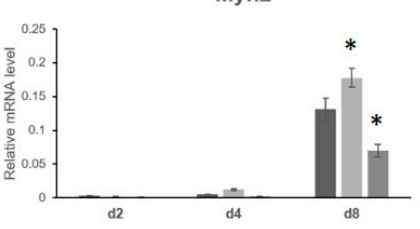

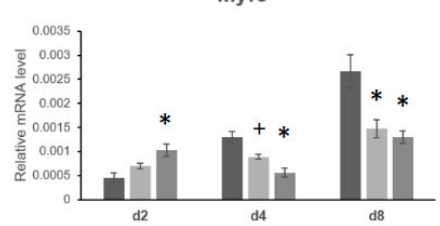

MyoD1

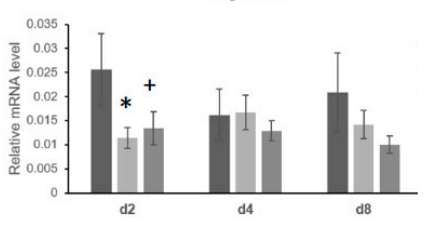

- BSA50

- AA50

- DHA50
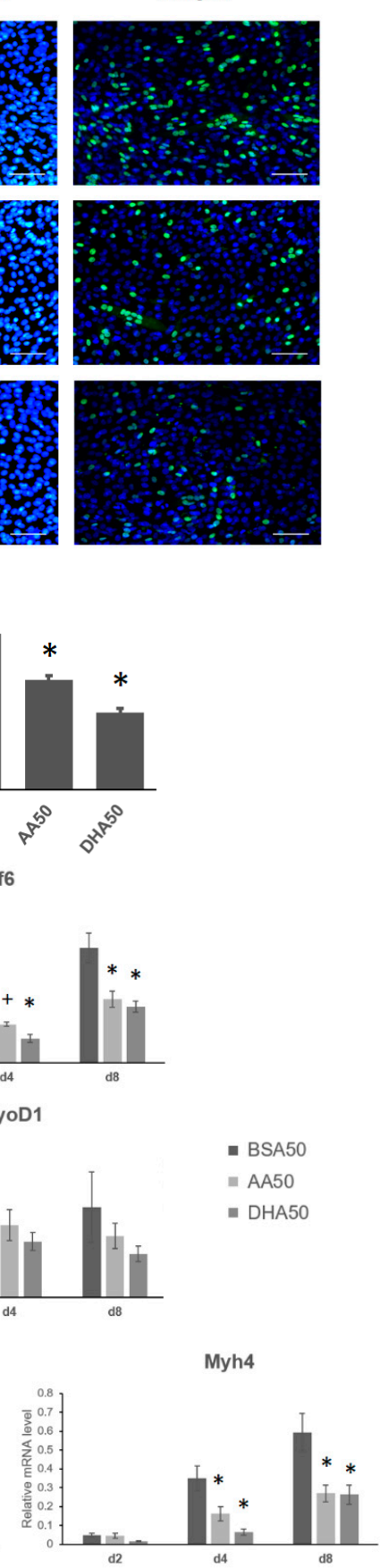

Figure 4. The effect of $50 \mu \mathrm{M}$ PUFA on C2C12 myotubes formation. (a) Immunofluorescence staining using Anti-Myogenin Alexa Fluor ${ }^{\circledR} 488$ and Hoechst 33342 staining on C2C12 myotubes at day 2 (d2) of the treatment. Scale bar for live cells is $100 \mu \mathrm{m}$, Scale bar for anti-myogenin Alexa488, Hoechst 33342 staining and merged is $200 \mu \mathrm{M}$. (b) Quantification of differentiation index and fusion index are shown. The mRNA level of myogenesis markers at three time points (d2 (2 days treatment), $\mathrm{d} 4$ ( 2 days treatment plus 2 days recovery), d8 ( 2 days treatment plus 6 days recovery)) was shown. (c) At d2, Myf5 expression level was induced in both AA50 and DHA50 treatment. MyoG expression level was significantly decreased in both AA50 and DHA50 treatment. MyoD1 expression level was significantly decreased in AA50 and DHA50 treatments. The expression level of Myf6 was significantly increased in DHA50 at $\mathrm{d} 2$ and decreased at d4, but significantly decreased in both AA50 and DHA50 at d8. (d) The expression level of Myh1 was significantly decreased in d2, d4 and d8 in DHA50, also significantly decreased in AA50 at d4. The expression level of Myh2 was significantly increased in AA50 and significantly decreased in DHA50 at d8. The expression levels of Myh4 significantly decreased at d4 and d8 in both AA50 and DHA50. All values are LS means \pm SEM, + indicate $p<0.1$ and * indicates $p<0.05$ treatment vs. control group BSA50. 
The level of Myf5 mRNA was significantly increased whereas MyoG mRNA was significantly decreased at 2 days of AA20, DHA20, AA50 and DHA50 treatment (Figure 3c or Figure 4c). The transcript level of Myf6 was significantly increased in DHA50 and of Myh1 was significantly decreased in DHA20 and DHA50 after 2 days of treatment (Figure $3 \mathrm{~d}$ or Figure $4 \mathrm{~d}$ ). The transcript level of MyoD1 tended to be reduced compared to control (BSA) and was significantly reduced only at d2 with AA50 and DHA50 treatment. After 4 days of treatment, the changes in transcript abundances were significant for Myf6 (DHA20, AA50, DHA50), Myh1 (DHA20, AA50, DHA50), Myh2 (AA20, DHA20, AA50, DHA50), and Myh4 (DHA20, AA50, DHA50). Until six days after removal of PUFA treatment (d8), AA and DHA still affected myogenesis and Myf6 mRNA was decreased in all treatments (Figure 3c or Figure 4c). In addition, changes in mRNA level of myosin heavy chain markers Myh1, Myh2 and Myh4, which are more specific to fiber types, were obvious in all treatments except for Myh1 in AA50.

\subsection{Morphological Changes after 6 Days Recovery}

Our data show that AA and DHA treatment changed the myogenic differentiation (Figures 5 and 6). Both AA20 and DHA20 slowed differentiation after 2 days of treatment. However, after switching back to only DM, the treated cells showed low numbers of myotubes formation on $\mathrm{d} 4$ than on $\mathrm{d} 8$. This was confirmed by transcript levels of developmental late isoforms (Myh1, Myh2 and Myh4) which were lower on d4 and higher on day 8. In BSA control, more elongated myotubes were observed compared to treated cells. These results show that AA and DHA treatments induced changes in the cell morphology and caused a delay in the differentiation timeline of cells.
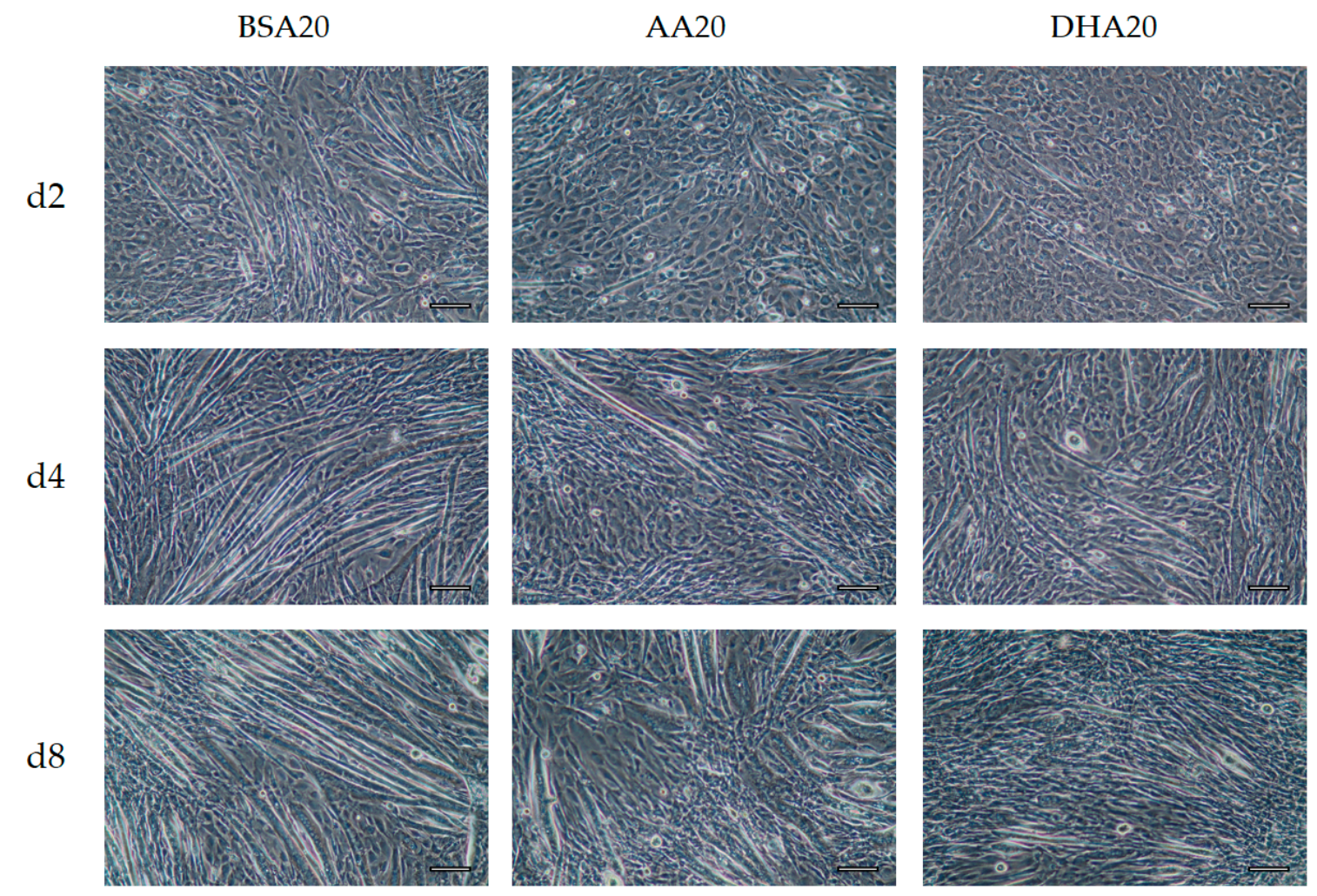

Figure 5. The phase contrast images of $\mathrm{C} 2 \mathrm{C} 12$ differentiation stages under different treatments at different time points (Day 2 (d2), Day 4 (d4) and Day 8 (d8)). BSA20, AA20 and DHA20 treatments were added only on the first 2 days and then switched with normal DM medium till day 8 . Scale bar $100 \mu \mathrm{m}$. 

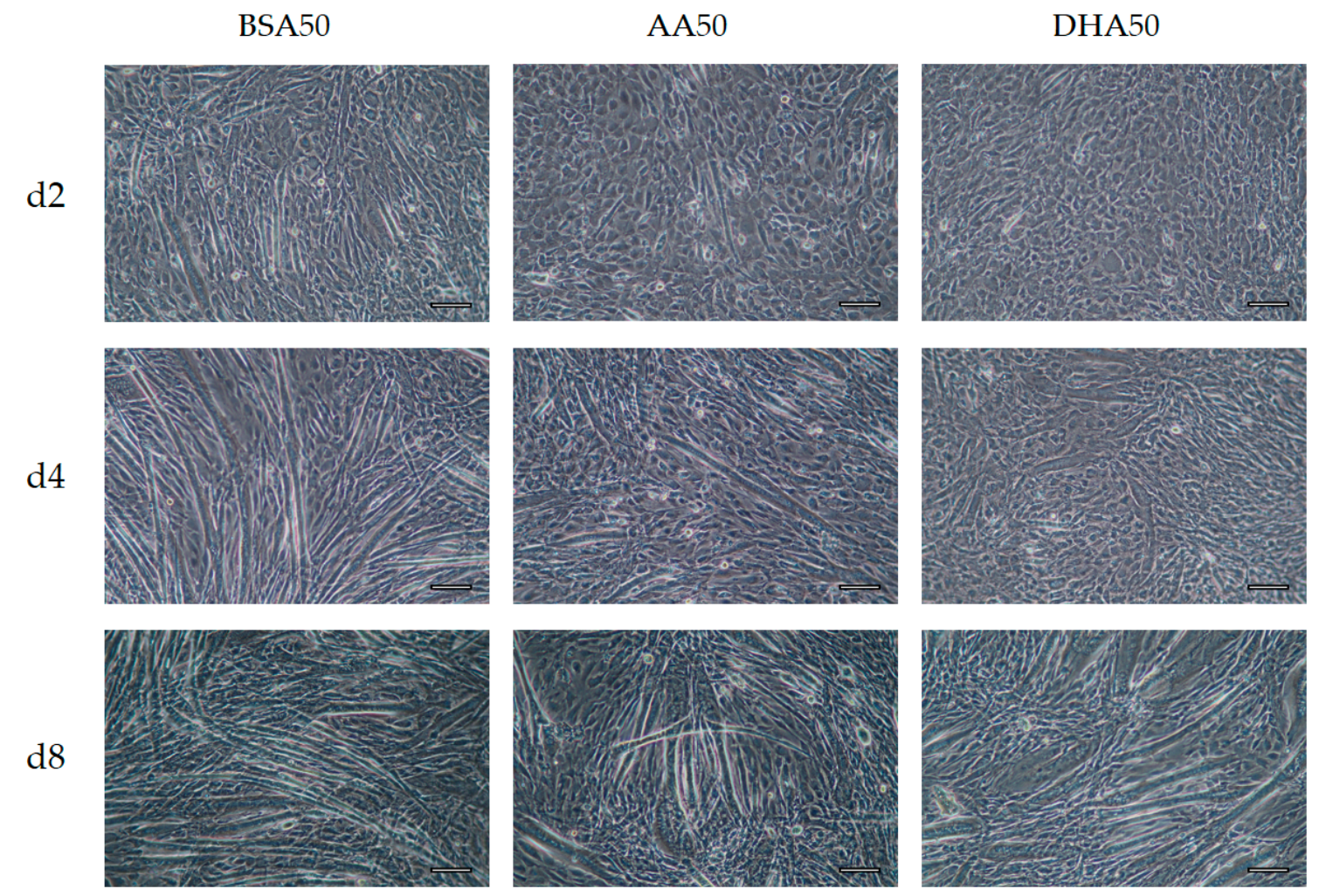

Figure 6. The phase contrast images of $\mathrm{C} 2 \mathrm{C} 12$ differentiation stages under different treatments at different time points (Day 2 (d2), Day 4 (d4) and Day 8 (d8)). BSA50, AA50 and DHA50 treatments were added only on the first 2 days and then switched with normal DM medium till day 8. Scale bar $100 \mu \mathrm{m}$.

\subsection{AA and DHA Affects the mRNA Abundance of Genes Involved in Wnt Signaling Pathway}

Wnt signaling pathways are involved in cell differentiation. Selection of candidate Wnt pathway genes were based on their role in the pathway including inhibitors, regulators, receptor and key transcripts in specific parts of Wnt/PCP, Wnt/Ca+2, and Wnt/ $\beta$-Catenin pathways. PUFA treated cells showed changes in mRNA level of three genes (Axin2, Wif1 and Znrf3) involved in negative regulation of Wnt signaling pathway (Figure 7). Axin 2 mRNA was significantly increased after 2 days of AA20 and DHA20 treatments, however this increase did not reach significance in AA50 and DHA50 treatments. At day 8, Axin2 mRNA level was significantly decreased in all treated cells (AA20, DHA20, AA50 and DHA50). There was a significant increase in Wif1 mRNA in AA-treated samples at day 4 , but it was significantly decreased at day 8 . We found that, at day 2 , the transcripts abundance of Znrf3 was significantly increased in both AA20 and DHA20. Genes involved in Wnt/PCP pathway (Daam1 and Rac1) were significantly increased at day 2. 


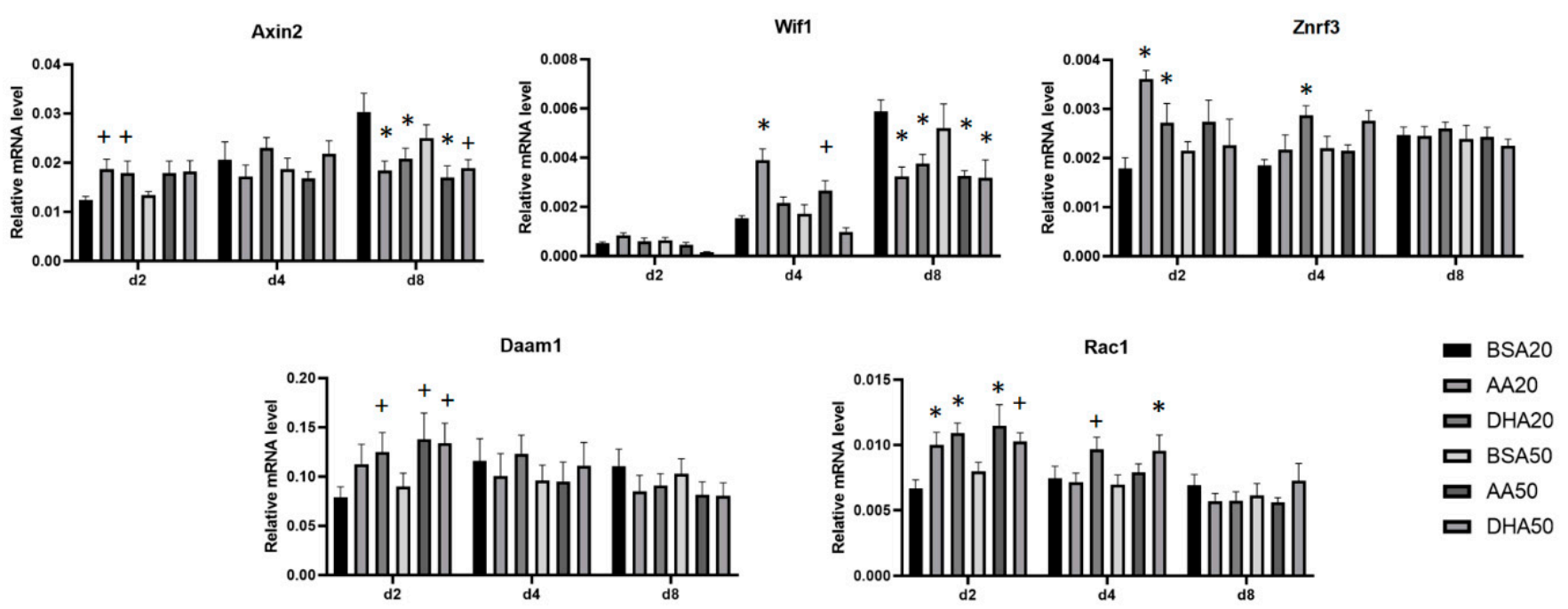

Figure 7. The mRNA levels of negative regulators of Wnt signaling pathway at three time points, i.e., 2 days treatment (d2), day 4 (d4; 2 days treatment +2 days recovery) and day 8 (d8; 2 days treatment +6 days recovery). The mRNA levels of $A x i n$ and Znrf3 were increased at $\mathrm{d} 2$ relatively on all treated cells. The mRNA levels of Wif1 and Axin2 were decreased in all treated cells at day 8. All values are LS means \pm SEM, + indicate $p<0.1$ and * indicate $p<0.05$ treatment vs. respective BSA control group.

\subsection{AA and DHA Affects Myoblasts Energy Metabolism}

To investigate whether DHA and AA treatments are involved in mitochondrial bioenergetics properties of $\mathrm{C} 2 \mathrm{C} 12$ cells, the metabolic flux was analyzed by measuring the intracellular oxygen consumption rate (OCR). The OCR profiles before and after oligomycin, FCCP and antimycin-A injections in control (BSA) and treated cells (AA and DHA) were presented in Figure 8a. The ECAR profiles before and after glucose, oligomycin and 2-DG injections in control (BSA) and treated cells (AA and DHA) were shown in Figure 8b. No significant changes were found on the levels of basal respiration and proton leak of myoblasts after $48 \mathrm{~h}$ of treatment with AA20, DHA20 and AA50. However, both basal respiration and proton leak parameters were significantly lowered after treatment with DHA50 (Figure 8c). In addition, significant differences were found between AA and DHA treatments where AA seemed to increase OCR, while DHA tended to lower it in many mitochondrial parameters like basal respiration, ATP production and proton leak. There were no significant changes in glycolysis or glycolytic capacity of cells after PUFA treatments (Figure 8d). To explore the effect of AA and DHA on gene expression involved in mitochondrial biogenesis, we measured mRNA levels of PGC-1alpha, Sirt1 and Prkaa1 (Figure 8e). Significant changes in RNA expression were noticed in day 2; the transcripts level of PGC-1alpha was significantly increased in treated cells (AA20, AA50) compare to control (BSA20, BSA50) while Sirt1 mRNA was significantly increased in AA20 and DHA20 compared to BSA20. The expression of Prkaa1 was significantly increased in treated cells (DHA20 and DHA50) compared to control (BSA20, BSA50). 
(a)

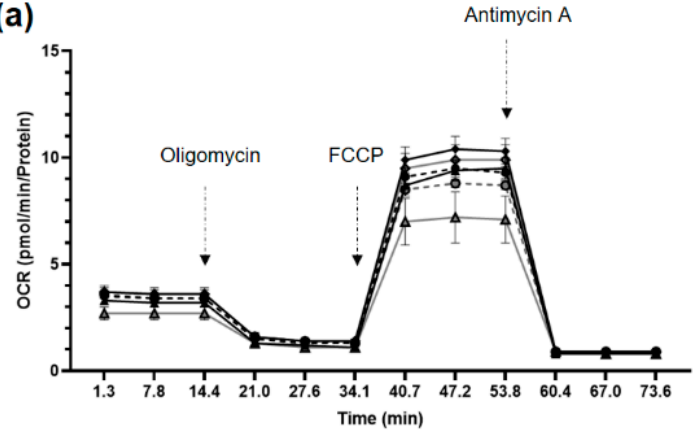

(c)

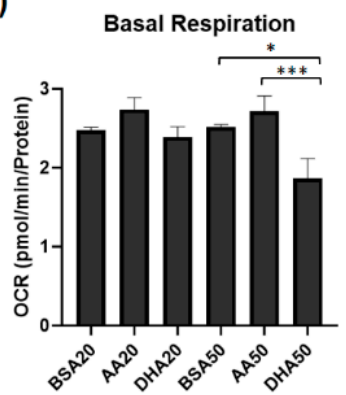

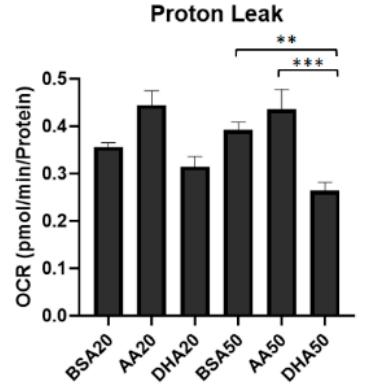

(b)

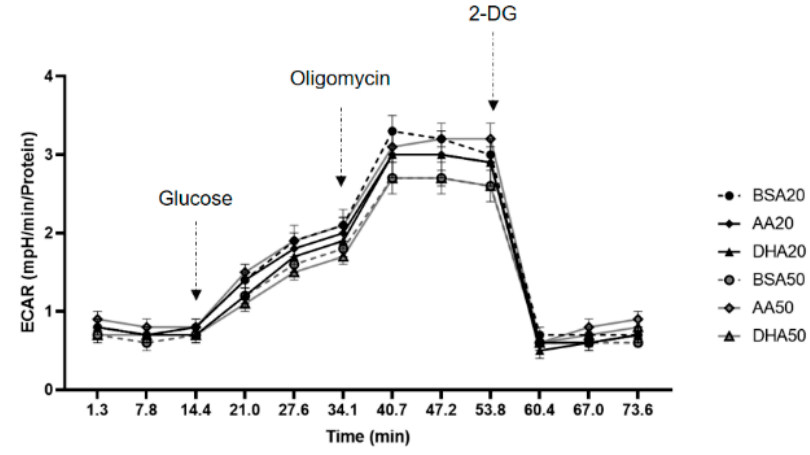

(d)

Glycolytic Capacity
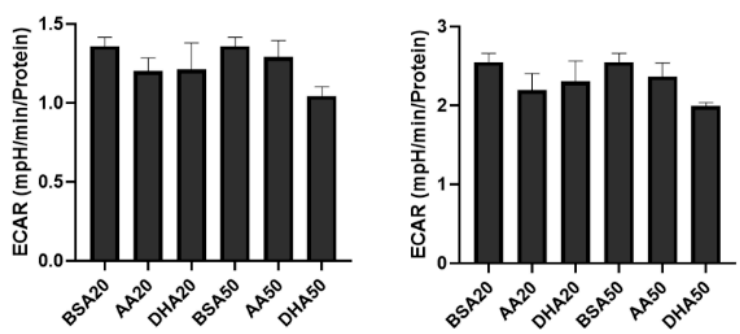

(e)

day 2

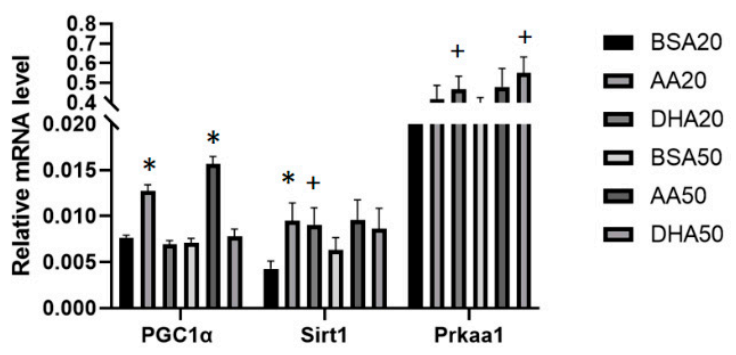

Figure 8. Bioenergetics metabolism in $\mathrm{C} 2 \mathrm{C} 12$ under 2 days of AA and DHA treatments. (a) Mitochondrial respiration and (b) Glycolytic function in C2C12 cells in culture with different treatments; AA20, AA50, DHA20, DHA50, the controls BSA20 and BSA50. (c) The effect of AA50 and DHA 50 on the basal respiration and proton leak. (d) No effect of PUFA treatments on the glycolysis and glycolytic reserve. All data are from six well of 3000 cells/well per treatment. All values are LS means \pm SEM given in pmol $\mathrm{O}_{2} / \mathrm{min} / \mu \mathrm{g}$ protein. ${ }^{*} p<0.1,{ }^{* *} p<0.05$ and ${ }^{* * *} p<0.001$. (e) The mRNA levels of PGC-1alpha, Sirt1 and Prkaa1; the mRNA levels of PGC-1alpha were significantly increased with AA treatments in both concentration $(20$ and $50 \mu \mathrm{M})$. The mRNA levels of Prkaa1 were significantly increased with DHA20 and DHA50. Sirt1 mRNA levels were significantly increased with DHA and AA with $20 \mu \mathrm{M}$. All values are LS means \pm SEM, $+p<0.1$ and * $p<0.05$.

\section{Discussion}

N-3 and n-6 polyunsaturated fatty acids play an essential role in the development of skeletal muscle $[29,30]$. This study aimed to access the impact of PUFA on myogenesis and in particular on the major myogenic regulatory factors including MyoG, MyoD1, Myf5 and Myf6. Previous studies have demonstrated both positive and negative impacts of PUFA on myogenesis. The positive influence of AA on the size of muscle cells in the existing myotubes has already been mentioned [31], and as well as the effect influence of other types of PUFAs on cell proliferation and differentiation has been previously described [12,13]. Previous studies have shown the role of n3-PUFA on muscle growth, regeneration, satellite cells programming, mitochondrial biosynthesis and modulation of skeletal muscle lipid raft composition [26,32-34]. The impact of a PUFA depends on the concentration used, duration of treatment, time point of treatment and the method of treatment [35]. In our 
experiment, we used BSA as a transporter for PUFA with a ratio of 1:4. Satellite cells are skeletal muscle cell precursors that can regenerate muscle cells during postnatal growth or regenerate skeletal muscle in adults in response to muscle injury. Muscle regeneration processes are sensitive and can be influenced by inflammatory processes [36]. Many n-3 PUFAs are known for their anti-inflammatory properties [37]. Evidence including $3 n-$ PUFA's role in satellite cells activation suggests the possible involvement of 3n-PUFA in the regeneration process during injury [26]. However, PUFA's affects the transition period from proliferating phase to differentiation phase of muscle cells remains unclear. In this study, AA and DHA treatment affected Myf5, MyoG, Myf6, and MyoD1. Myf5 mRNA was increased whereas $M y o G$ and MyoD1 mRNAs were decreased. Myf5 facilitates early stage of myoblast proliferation [38]. As shown in our results, Myf5 mRNA was reduced at day 4 and day 8. At day 2, the transcript level of Myf5 was higher in the AA and DHA treated cells indicating increased myoblast proliferation. Overexpression of Myf5 leads to upregulation of Cyclin D1, which reflects the transition from G1 to S stage in cell cycle $[38,39]$. DHA was reported to decrease mRNA and protein levels of both cyclin E and CDK2 during C2C12 proliferation and keeping the cells in G1 phase for longer [40]. MyoD and MyoG act together with myocyte enhancer factor 2 (MEF2) to drive myoblast differentiation [5]. MyoG expression marks the end of myoblast proliferation and induces differentiation of myoblasts including fusion to form multinucleated muscle myotubes [41,42]. Our data show that under PUFA treatment, there were fewer differentiated myotubes but more proliferative myoblasts as a result of prolonged proliferation and delayed differentiation. In contrast, in a study with L6C5 cells AA and DHA and, to a lesser extent, also EPA induced a significantly increased formation of myotubes after 4 days of incubation with $20 \mu \mathrm{M}$ of PUFAs compared to the control cells [34]. However, it was not clear whether in this study the L6C5 myoblasts were differentiated before treatment. In another study, $\mathrm{C} 2 \mathrm{C} 12$ myoblasts were subjected to $72 \mathrm{~h}$ of differentiation prior to AA supplementation, resulting in an increase in myotube size and protein content, but no differences in fusion and differentiation [31]. Recently, in a study with conditions similar to our study (48 h treatment with 25 or $50 \mu \mathrm{M}$ DHA or EPA), a reduction in transcripts and proteins of myogenic marker was found in $\mathrm{C} 2 \mathrm{C} 12$ myoblasts, suggesting that EPA and DHA suppress differentiation of $\mathrm{C} 2 \mathrm{C} 12$ myoblasts [14]. Together with the state of the cell, the effect of PUFA treatment varies depending on the dose and time.

Low concentration of DHA $(10 \mu \mathrm{M})$ stimulates cell proliferation whereas higher concentration of DHA $(100 \mu \mathrm{M})$ inhibits C2C12 cells proliferation [12,14]. In our study, real time monitoring of cell proliferation revealed that $100 \mu \mathrm{M}$ DHA significantly reduced myoblasts proliferation particularly in the growth phase during 24 to $36 \mathrm{~h}$ of treatment, whereas no change was observed after PUFA treatment at 20,30 and $50 \mu \mathrm{M}$ doses during 3 days of treatment. In the cell differentiation experiment, mRNA level of Myf5 was expressed higher at day 2 under PUFA treatment than in the control group. Myf5 is involved in early phase of myoblast proliferation, suggesting the prolongation of proliferation phase under PUFA treatment. In addition, PUFA treatment prevented myoblast differentiation as showed by decreased myotube fusion index and myotube differentiation index paralleled with decrease in mRNA levels of MyoG. These data suggest the role of PUFAs in the transition period between proliferation and differentiation stages in myogenesis process.

Skeletal muscles consist of various fiber types making them heterogeneous with each fiber having its own properties [43]. In this study, three different markers from fast twitch fibers (Myh1, Myh2 and Myh4) were chosen, that represent MyhHCIId/x, MyhHCIIa and MyhHCIlb fibers [44]. The transcripts levels of these genes increased along the culture days ( $\mathrm{d} 4$ and $\mathrm{d} 8$ ) in the control groups and were overall reduced by AA and DHA even after two and four days of recovery. This is in line with reduced myotube number and fusion index after AA and DHA treatments at both concentrations (20 and $50 \mu \mathrm{M})$ along with a downregulation of $M y o G$ mRNA expression level. This may play a substantial role in the expression of myosin heavy chain genes. The downregulation of Myf6 in late stage 
of the differentiation supports this claim. Our results are consistent with the previous study that showed the inhibitory effect of n-3 PUFAs on C2C12 myoblasts [14].

The potential effects of PUFAs on myogenesis may relate to their ability to alter the lipid composition of the cell membrane, and this alteration may lead to the modulation of various signaling pathways including Wnt signaling pathways. Wnt signaling pathways are key pathways in many biological processes including embryonic myogenesis [45,46]. Previous studies also showed the involvement of Wnt signaling cascades in development and maturation of different fiber types [44]. Therefore, we selected candidate genes based on their role in the Wnt pathway to study their response to PUFA treatment. Most of the transcripts in these pathways did not significantly change under PUFA treatment except Daam1, Rac1 as elements of the non-canonical PCP Wnt signaling cascade at day 2 and Axin2, Znrf3 and Wif1, which are involved in the Wnt/ $\beta$-Catenin pathway. The high expression of Daam1 and Rac1 could impact cytoskeleton regulation [47] and also promote cell proliferation [48]. DAAM1 plays a critical role in regulating the actin cytoskeleton and tissue morphogenesis as shown in Daam1-deficient mice [49]. Wnt signaling is known to promote cell proliferation. In our study, the high expression of Daam 1 and Rac1 under PUFA treatment may promote cell proliferation. Both AA and DHA treatments increased the expression of the negative regulators Wnt signaling (Axin2 and Znrf3). A previous study reported Axin2-dependent Wnt/ $\beta$-catenin signaling is involved in myotube formation and associated with reduced muscle fiber diameter of a subset of fast fibers [46]. It has been previously reported that $\omega-3$ PUFA negatively regulates nuclear and cytoplasmic level of $\beta$-Catenin in HepG2 cells [50]. In our study, AA particularly increased Wnt ligand inhibitor Wif1. WIF1 is considered a tumor suppressor and high concentration of n-3 PUFAs (above $100 \mu \mathrm{M}$ ) significantly increases Wifl expression in pancreatic cancer cell line (MIA PaCa-2) [51].

The proportion of cellular ATP production by glycolysis in the cytoplasm or oxidative phosphorylation (OXPHOS) in the mitochondria depends on many factors including stress condition [28]. In this study PUFA, treatment at doses of 20 or $50 \mu \mathrm{M}$ has no effect on proliferation but prevented the myoblast differentiation. It is therefore interesting to know whether the mitochondrial bioenergetics properties of the mitochondria change under PUFA treatment. During stress response, the lactate-to-pyruvate ratios were increased, indicating a higher rate of glycolysis and reduced OXPHOS [52]. No significant change of the basal respiration, proton leak, glycolysis and glycolytic capacity was found under low concentration $(20 \mu \mathrm{M})$ of both AA and DHA. The mitochondrial respiration slightly changed in the higher concentration $(50 \mu \mathrm{M})$ of both AA and DHA. DHA treatments exhibit reduction in the basal respiration and proton leak in compared to the control BSA and both parameters were higher in AA treatment. DHA can incorporation into mitochondrial membranes [53]. These results suggest that high levels of DHA preserve mitochondrial integrity by incorporation into mitochondrial membranes.

PGC- $1 \alpha$ is considered the master regulator for mitochondrial biogenesis [54]. The level of PGC-1 $\alpha$ mRNA is significantly correlated with the expression of both mitochondrial and nuclear encoded OXPHOS subunits, as well as with the enzyme activities of complex I, II, and IV [55]. Interestingly, we found an increase in Pgc-1 $\alpha$ mRNA levels in AA treated samples while expression levels of Sirt1 was increased under both AA and DHA treatments. The tendency of intracellular oxygen consumption rate was also higher in AA treated samples. In a previous study, it was shown that the 20-carbon EPA (20:5n-3) and AA prompted higher incorporation into the mitochondrial inner membranes than 22-carbon DHA [56]. Fatty acid oxidation occurs within mitochondria, the higher expression of PGC-1 $\alpha$ under AA treatment may be involve in this process. SIRT1 and AMPK $\alpha 1$ (Prkaa1) are nutrient sensors and their expressions and activities were reported to be increased after DHA treatment in macrophages [57]. Similar findings were reported in female Wistar rats fed with low proportion of n3 PUFA, where it showed an increase in Sirt1 and PgC$1 \alpha$ gene expression [58]. We found an increased in Sirt1 mRNA levels in AA and DHA treated samples, which are consistent with previous studies. Two potential effects of 
PUFAs on energy metabolism may be related to their ability to incorporate into the inner mitochondrial membranes, and this change may lead to alteration in metabolic pathways in mitochondria.

In summary, our results show that PUFA treatment immediately increased mRNA levels of Myf5, which is involved in the early stage of myoblast proliferation. At the same time PUFA treatment decreased mRNA levels of MyoG. This is accompanied by prevented myoblast differentiation, as demonstrated by a decreased myotube fusion index and myotube differentiation index. Thus, this study of polyunsaturated fatty acids on myogenesis suggests that their influence is exerted on the disruption of the early phases. Some of the transcripts in the Wnt/ $\beta$ catenin and Wnt/PCP signaling pathways, including Axin2, Znrf3, Wif1, Daam1 and Rac1, changed under PUFA treatment. No change in glycolysis and glycolytic capacity was observed under PUFA treatment. In addition, high DHA treatments showed a reduction in the basal respiration and proton leakage compared to the BSA control group, suggesting that high DHA concentrations may preserve mitochondrial integrity by incorporation into mitochondrial membranes. Finally, PUFA treatment increased key transcripts of mitochondrial energy metabolism including Sirt1 and PGC-1 $\alpha$ and Prkaa1.

Supplementary Materials: The following are available online at https:/ /www.mdpi.com/2073-442 5/12/2/192/s1, Supplementary Table S1: Primers sequences used for amplification in qPCR. The table include information of primer sequence and the gene symbol.

Author Contributions: Conceptualization, S.P. and D.D.; Methodology, D.D. and P.S.; Formal Analysis, M.A.R. and S.P.; Investigation, M.A.R.; Writing-Original Draft Preparation, M.A.R.; WritingReview and Editing, S.P., D.D., K.W. and P.S.; Supervision, K.W., D.D., S.P. and P.S.; Project Administration, S.P. All authors have read and agreed to the published version of the manuscript.

Funding: This research was funded by the Doctoral Project Competition of the Leibniz Institute for Farm Animal Biology (FBN).

Institutional Review Board Statement: Not applicable.

Informed Consent Statement: Not applicable.

Data Availability Statement: The data (figures and table) used to support the findings of this study are included within the article.

Acknowledgments: We thank our technical assistants Joana Bittner, Annette Jugert and Nicole Gentz for their excel-lent work on this project. Special thanks to Asghar Ali for the manuscript correction.

Conflicts of Interest: The authors declare that they have no competing interest.
Abbreviations
PUFAs Polyunsaturated fatty acids
DHA Docosahexaenoic acid
AA Arachidonic acid
Myh1 Myosin Heavy Chain 1
Myh2 Myosin Heavy Chain 2
Myh4 Myosin Heavy Chain 4
Myf6 Myogenic Factor 6
Myf5 Myogenic Factor 5
MyoG Myogenin
MyoD Myogenic myogenic differentiation
Daam1 Dishevelled Associated Activator of Morphogenesis 1
Znrf3 Zinc and Ring Finger 3
Wif1 Wnt Inhibitory Factor 1 


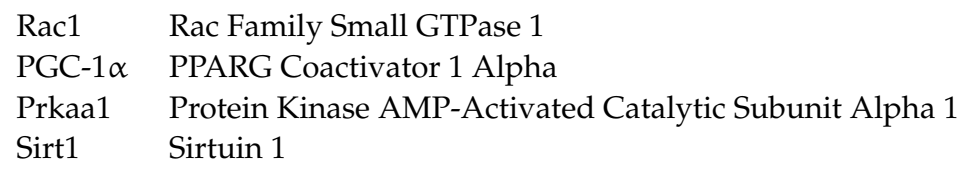

\section{References}

1. Friedrichs, M.; Wirsdöerfer, F.; Flohé, S.B.; Schneider, S.; Wuelling, M.; Vortkamp, A. BMP signaling balances proliferation and differentiation of muscle satellite cell descendants. BMC Cell Biol. 2011, 12, 26. [CrossRef] [PubMed]

2. Straface, G.; Aprahamian, T.; Flex, A.; Gaetani, E.; Biscetti, F.; Smith, R.C.; Pecorini, G.; Pola, E.; Angelini, F.; Stigliano, E.; et al. Sonic hedgehog regulates angiogenesis and myogenesis during post-natal skeletal muscle regeneration. J. Cell Mol. Med. 2009, 13, 2424-2435. [CrossRef] [PubMed]

3. Moncaut, N.; Rigby, P.W.; Carvajal, J.J. Dial M(RF) for myogenesis. FEBS J. 2013, 280, 3980-3990. [CrossRef] [PubMed]

4. Ott, M.O.; Bober, E.; Lyons, G.; Arnold, H.; Buckingham, M. Early expression of the myogenic regulatory gene, myf-5, in precursor cells of skeletal muscle in the mouse embryo. Development 1991, 111, 1097. [PubMed]

5. Knight, J.D.R.; Kothary, R. The myogenic kinome: Protein kinases critical to mammalian skeletal myogenesis. Skelet. Muscle 2011, 1, 29. [CrossRef] [PubMed]

6. Buonanno, A.; Apone, L.; Morasso, M.I.; Beers, R.; Brenner, H.R.; Eftimie, R. The MyoD family of myogenic factors is regulated by electrical activity: Isolation and characterization of a mouse Myf-5 cDNA. Nucleic Acids Res. 1992, 20, 539-544. [CrossRef] [PubMed]

7. Demonbreun, A.R.; Biersmith, B.H.; McNally, E.M. Membrane fusion in muscle development and repair. Semin. Cell Dev. Biol. 2015, 45, 48-56. [CrossRef]

8. Simons, K.; Ikonen, E. Functional rafts in cell membranes. Nature 1997, 387, 569-572. [CrossRef]

9. Calder, P.C. n-3 polyunsaturated fatty acids, inflammation, and inflammatory diseases. Am. J. Clin. Nutr. 2006, 83, 1505s-1519s. [CrossRef]

10. Calder, P.C. Polyunsaturated fatty acids, inflammation, and immunity. Lipids 2001, 36, 1007-1024. [CrossRef]

11. Fournier, N.; Benoist, J.-F.; Allaoui, F.; Nowak, M.; Dakroub, H.; Vedie, B.; Paul, J.-L. Contrasting effects of membrane enrichment with polyunsaturated fatty acids on phospholipid composition and cholesterol efflux from cholesterol-loaded J774 mouse or primary human macrophages. Biochim. Biophys. Acta Mol. Cell Biol. Lipids 2020, 1865, 158536. [CrossRef] [PubMed]

12. Lee, J.H.; Tachibana, H.; Morinaga, Y.; Fujimura, Y.; Yamada, K. Modulation of proliferation and differentiation of C2C12 skeletal muscle cells by fatty acids. Life Sci. 2009, 84, 415-420. [CrossRef] [PubMed]

13. Hurley, M.S.; Flux, C.; Salter, A.M.; Brameld, J.M. Effects of fatty acids on skeletal muscle cell differentiation in vitro. Br. J. Nutr. 2006, 95, 623-630. [CrossRef] [PubMed]

14. Zhang, J.; Xu, X.; Liu, Y.; Zhang, L.; Odle, J.; Lin, X.; Zhu, H.; Wang, X.; Liu, Y. EPA and DHA Inhibit Myogenesis and Downregulate the Expression of Muscle-related Genes in C2C12 Myoblasts. Genes 2019, 10, 64. [CrossRef] [PubMed]

15. Andersson, A.; Nalsen, C.; Tengblad, S.; Vessby, B. Fatty acid composition of skeletal muscle reflects dietary fat composition in humans. Am. J. Clin. Nutr. 2002, 76, 1222-1229. [CrossRef] [PubMed]

16. Philipsen, M.H.; Sämfors, S.; Malmberg, P.; Ewing, A.G. Relative quantification of deuterated omega-3 and -6 fatty acids and their lipid turnover in PC12 cell membranes using TOF-SIMS. J. Lipid Res. 2018, 59, 2098-2107. [CrossRef] [PubMed]

17. Shaikh, S.R.; Kinnun, J.J.; Leng, X.; Williams, J.A.; Wassall, S.R. How polyunsaturated fatty acids modify molecular organization in membranes: Insight from NMR studies of model systems. Biochim. Biophys. Acta 2015, 1848, 211-219. [CrossRef] [PubMed]

18. Glatz, J.F.C.; Luiken, J.J.F.P. Fatty acids in cell signaling: Historical perspective and future outlook. Prostaglandins Leukot. Essent. Fat. Acids 2015, 92, 57-62. [CrossRef] [PubMed]

19. Cossu, G.; Borello, U. Wnt signaling and the activation of myogenesis in mammals. EMBO J. 1999, 18, 6867-6872. [CrossRef]

20. Linker, C.; Lesbros, C.; Gros, J.; Burrus, L.W.; Rawls, A.; Marcelle, C. Beta-Catenin-dependent Wnt signalling controls the epithelial organisation of somites through the activation of paraxis. Development 2005, 132, 3895-3905. [CrossRef]

21. Otto, A.; Schmidt, C.; Luke, G.; Allen, S.; Valasek, P.; Muntoni, F.; Lawrence-Watt, D.; Patel, K. Canonical Wnt signalling induces satellite-cell proliferation during adult skeletal muscle regeneration. J. Cell Sci. 2008, 121, 2939-2950. [CrossRef]

22. Sokol, S.Y. Maintaining embryonic stem cell pluripotency with Wnt signaling. Development 2011, 138, 4341. [CrossRef] [PubMed]

23. Zhan, T.; Rindtorff, N.; Boutros, M. Wnt signaling in cancer. Oncogene 2017, 36, 1461-1473. [CrossRef] [PubMed]

24. Cavaliere, G.; Trinchese, G.; Bergamo, P.; De Filippo, C.; Mattace Raso, G.; Gifuni, G.; Putti, R.; Moni, B.H.; Canani, R.B.; Meli, R.; et al. Polyunsaturated Fatty Acids Attenuate Diet Induced Obesity and Insulin Resistance, Modulating Mitochondrial Respiratory Uncoupling in Rat Skeletal Muscle. PLoS ONE 2016, 11, e0149033. [CrossRef] [PubMed]

25. da Silva, E.P., Jr.; Nachbar, R.T.; Levada-Pires, A.C.; Hirabara, S.M.; Lambertucci, R.H. Omega-3 fatty acids differentially modulate enzymatic anti-oxidant systems in skeletal muscle cells. Cell Stress Chaperones 2016, 21, 87-95. [CrossRef] [PubMed]

26. Tachtsis, B.; Camera, D.; Lacham-Kaplan, O. Potential Roles of n-3 PUFAs during Skeletal Muscle Growth and Regeneration. Nutrients 2018, 10, 309. [CrossRef] [PubMed]

27. Kho, D.; MacDonald, C.; Johnson, R.; Unsworth, C.P.; O'Carroll, S.J.; du Mez, E.; Angel, C.E.; Graham, E.S. Application of xCELLigence RTCA Biosensor Technology for Revealing the Profile and Window of Drug Responsiveness in Real Time. Biosensors 2015, 5, 199-222. [CrossRef] 
28. Sajjanar, B.; Siengdee, P.; Trakooljul, N.; Liu, X.; Kalbe, C.; Wimmers, K.; Ponsuksili, S. Cross-talk between energy metabolism and epigenetics during temperature stress response in C2C12 myoblasts. Int. J. Hyperth. Off. J. Eur. Soc. Hyperthermic Oncol. North Am. Hyperth. Group 2019, 36, 776-784. [CrossRef]

29. Abdelhamid, A.; Hooper, L.; Sivakaran, R.; Hayhoe, R.P.G.; Welch, A. The Relationship Between Omega-3, Omega-6 and Total Polyunsaturated Fat and Musculoskeletal Health and Functional Status in Adults: A Systematic Review and Meta-analysis of RCTs. Calcif. Tissue Int. 2019, 105, 353-372. [CrossRef]

30. Jeromson, S.; Gallagher, I.J.; Galloway, S.D.R.; Hamilton, D.L. Omega-3 Fatty Acids and Skeletal Muscle Health. Mar. Drugs 2015, 13, 6977-7004. [CrossRef]

31. Markworth, J.F.; Cameron-Smith, D. Arachidonic acid supplementation enhances in vitro skeletal muscle cell growth via a COX-2-dependent pathway. Am. J. Physiol.-Cell Physiol. 2012, 304, C56-C67. [CrossRef]

32. Bhullar, A.S.; Putman, C.T.; Mazurak, V.C. Potential Role of Omega-3 Fatty Acids on the Myogenic Program of Satellite Cells. Nutr. Metab. Insights 2016, 9, 1-10. [CrossRef] [PubMed]

33. Hsueh, T.-Y.; Baum, J.I.; Huang, Y. Effect of Eicosapentaenoic Acid and Docosahexaenoic Acid on Myogenesis and Mitochondrial Biosynthesis during Murine Skeletal Muscle Cell Differentiation. Front. Nutr. 2018, 5. [CrossRef] [PubMed]

34. Briolay, A.; Jaafar, R.; Nemoz, G.; Bessueille, L. Myogenic differentiation and lipid-raft composition of L6 skeletal muscle cells are modulated by PUFAs. Biochim. Biophys. Acta 2013, 1828, 602-613. [CrossRef] [PubMed]

35. Alsabeeh, N.; Chausse, B.; Kakimoto, P.A.; Kowaltowski, A.J.; Shirihai, O. Cell culture models of fatty acid overload: Problems and solutions. Biochim. Biophys. Acta Mol. Cell Biol. Lipids 2018, 1863, 143-151. [CrossRef] [PubMed]

36. Relaix, F.; Marcelle, C. Muscle stem cells. Curr. Opin. Cell Biol. 2009, 21, 748-753. [CrossRef] [PubMed]

37. Gil, A. Polyunsaturated fatty acids and inflammatory diseases. Biomed. Pharmacother. 2002, 56, 388-396. [CrossRef]

38. Panda, A.C.; Abdelmohsen, K.; Martindale, J.L.; Di Germanio, C.; Yang, X.; Grammatikakis, I.; Noh, J.H.; Zhang, Y.; Lehrmann, E.; Dudekula, D.B.; et al. Novel RNA-binding activity of MYF5 enhances Ccnd1/Cyclin D1 mRNA translation during myogenesis. Nucleic Acids Res. 2016, 44, 2393-2408. [CrossRef]

39. Kitzmann, M.; Carnac, G.; Vandromme, M.; Primig, M.; Lamb, N.J.; Fernandez, A. The muscle regulatory factors MyoD and myf-5 undergo distinct cell cycle-specific expression in muscle cells. J. Cell Biol. 1998, 142, 1447-1459. [CrossRef]

40. Peng, Y.; Zheng, Y.; Zhang, Y.; Zhao, J.; Chang, F.; Lu, T.; Zhang, R.; Li, Q.; Hu, X.; Li, N. Different effects of omega-3 fatty acids on the cell cycle in C2C12 myoblast proliferation. Mol. Cell Biochem. 2012, 367, 165-173. [CrossRef]

41. Lindon, C.; Montarras, D.; Pinset, C. Cell cycle-regulated expression of the muscle determination factor Myf5 in proliferating myoblasts. J. Cell Biol. 1998, 140, 111-118. [CrossRef] [PubMed]

42. Malik, A.; Lee, E.J.; Jan, A.T.; Ahmad, S.; Cho, K.-H.; Kim, J.; Choi, I. Network Analysis for the Identification of Differentially Expressed Hub Genes Using Myogenin Knock-down Muscle Satellite Cells. PLoS ONE 2015, 10, e0133597. [CrossRef] [PubMed]

43. Schiaffino, S.; Reggiani, C. Fiber types in mammalian skeletal muscles. Physiol. Rev. 2011, 91, 1447-1531. [CrossRef] [PubMed]

44. Mathew, S.J.; Hansen, J.M.; Merrell, A.J.; Murphy, M.M.; Lawson, J.A.; Hutcheson, D.A.; Hansen, M.S.; Angus-Hill, M.; Kardon, G. Connective tissue fibroblasts and Tcf4 regulate myogenesis. Development 2011, 138, 371-384. [CrossRef]

45. von Maltzahn, J.; Chang, N.C.; Bentzinger, C.F.; Rudnicki, M.A. Wnt signaling in myogenesis. Trends Cell Biol. 2012, $22,602-609$. [CrossRef]

46. Huraskin, D.; Eiber, N.; Reichel, M.; Zidek, L.M.; Kravic, B.; Bernkopf, D.; von Maltzahn, J.; Behrens, J.; Hashemolhosseini, S. Wnt/ $\beta$-catenin signaling via Axin2 is required for myogenesis and, together with YAP/Taz and Tead1, active in IIa/IIx muscle fibers. Development 2016, 143, 3128-3142. [CrossRef]

47. Hall, A. Rho GTPases and the actin cytoskeleton. Science 1998, 279, 509-514. [CrossRef]

48. Su, J.; Li, H. RAC1 overexpression promotes the proliferation, migration and epithelial-mesenchymal transition of lens epithelial cells. Int. J. Clin. Exp. Pathol. 2015, 8, 10760-10767.

49. Li, D.; Hallett, M.A.; Zhu, W.; Rubart, M.; Liu, Y.; Yang, Z.; Chen, H.; Haneline, L.S.; Chan, R.J.; Schwartz, R.J.; et al. Dishevelledassociated activator of morphogenesis 1 (Daam1) is required for heart morphogenesis. Development 2011, 138, 303-315. [CrossRef]

50. Chang, F.Z.; Wang, Q.; Zhang, Q.; Chang, L.L.; Li, W. Omega-3 polyunsaturated fatty acid inhibits the malignant progression of hepatocarcinoma by inhibiting the Wnt/beta-catenin pathway. Eur Rev. Med. Pharmacol. Sci. 2018, 22, 4500-4508. [CrossRef]

51. Rahmani, B.; Hamedi Asl, D.; Naserpour Farivar, T.; Azad, M.; Sahmani, M.; Gheibi, N. Omega-3 PUFA Alters the Expression Level but Not the Methylation Pattern of the WIF1 Gene Promoter in a Pancreatic Cancer Cell Line (MIA PaCa-2). Biochem. Genet 2019, 57, 477-486. [CrossRef] [PubMed]

52. Go, S.; Kramer, T.T.; Verhoeven, A.J.; Oude Elferink, R.P.J.; Chang, J.C. The extracellular lactate-to-pyruvate ratio modulates the sensitivity to oxidative stress-induced apoptosis via the cytosolic NADH/NAD(+) redox state. Apoptosis 2020. [CrossRef] [PubMed]

53. Herbst, E.A.F.; Paglialunga, S.; Gerling, C.; Whitfield, J.; Mukai, K.; Chabowski, A.; Heigenhauser, G.J.F.; Spriet, L.L.; Holloway, G.P. Omega-3 supplementation alters mitochondrial membrane composition and respiration kinetics in human skeletal muscle. J. Physiol. 2014, 592, 1341-1352. [CrossRef] [PubMed]

54. Ventura-Clapier, R.; Garnier, A.; Veksler, V. Transcriptional control of mitochondrial biogenesis: The central role of PGC-1alpha. Cardiovasc. Res. 2008, 79, 208-217. [CrossRef] 
55. Liu, X.; Trakooljul, N.; Hadlich, F.; Murani, E.; Wimmers, K.; Ponsuksili, S. Mitochondrial-nuclear crosstalk, haplotype and copy number variation distinct in muscle fiber type, mitochondrial respiratory and metabolic enzyme activities. Sci. Rep. 2017, 7, 14024. [CrossRef]

56. Chang, W.-H.; Ting, H.-C.; Chen, W.-W.; Chan, J.-F.; Hsu, Y.-H.H. Omega-3 and omega-6 fatty acid differentially impact cardiolipin remodeling in activated macrophage. Lipids Health Dis. 2018, 17, 201. [CrossRef]

57. Xue, B.; Yang, Z.; Wang, X.; Shi, H. Omega-3 polyunsaturated fatty acids antagonize macrophage inflammation via activation of AMPK/SIRT1 pathway. PLoS ONE 2012, 7, e45990. [CrossRef]

58. Reyes-Gordillo, K.; Shah, R.; Varatharajalu, R.; Garige, M.; Leckey, L.C.; Lakshman, M.R. Low-w3 Fatty Acid and Soy Protein Attenuate Alcohol-Induced Fatty Liver and Injury by Regulating the Opposing Lipid Oxidation and Lipogenic Signaling Pathways. Oxid. Med. Cell Longev. 2016, 2016, 1840513. [CrossRef] 